\title{
DESAIN LEMBAR KERJA MAHASISWA BERBASIS MODEL- ELICITING ACTIVITY PADA TOPIK RANGKAIAN HAMBATAN SERI DAN PARALEL
}

\author{
I Festiana ${ }^{1,2 *}$, H Firman ${ }^{1}$, A Setiawan ${ }^{1}$, and Muslim ${ }^{1}$ \\ ${ }^{1}$ Program Studi Pendidikan Ilmu Pengetahuan Alam, Sekolah Pascasarjana Universitas Pendidikan \\ Indonesia, J1. Dr. Setiabudi No. 229, Bandung 40154, Indonesia \\ ${ }^{2}$ Universitas Nahdlatul Ulama Lampung, Jl. Hanafiah Lintas Timur, Mataram Marga, Lampung Timur \\ 34394, Indonesia \\ Email: *ikefestiana@student.upi.edu
}

\begin{abstract}
The purpose of this research was to design student worksheet (LKM) based on modeleliciting activity in series and parallel circuit. This research is a development research using Design and Development Research methods (DDR) product and tool research with three specific project phases (analysis, design, and development). In the analysis phase an syllabus analysis and semester learning plan (RPS) were carried out, and the learning model applied. The results of the analysis phase was teachers centered and there was not model that can build coodinating between students. In the design phase, the design of LKM based the eliciting activity is designed. LKM was developed include three syntax, namely pre-reading, hands on demonstration, a model to predict series and parallel circuits. The results obtained at the time of development resulted in a LKM based modeleliciting activity that could train one of the skills in the industrial revolution 4.0, namely coordinating with others and being feasible to be processed on the of physics course.
\end{abstract}

Keywords: design and development research, Physics, model-eliciting activity

Abstrak: Tujuan dari penelitian ini adalah untuk mendesain lembar kerja mahasiswa berbasis modeleliciting activity pada materi rangkaian hambatan seri dan paralel. Penelitian ini merupakan penelitian pengembangan dengan menggunakan metode design and development research (DDR) penelitian produk dan alat dengan tiga fase spesifik (analisis, desain, dan pengembangan). Pada tahap analisis dilakukan analisis silabus dan rencana pembelajaran semester (RPS), dan observasi terhadap model pembelajaran yang diterapkan. Hasil pada tahap analisis adalah perkuliahan masih berpusat pada dosen dan belum digunakan model pembelajaran yang dapat membangun kerja sama antar mahasiswa. Pada tahapan desain dilakukan rancangan LKM berbasis model-eliciting activity. LKM dikembangkan meliputi tiga sintaks yaitu pre-reading, hands on demonstration, a model to predict series and parallel circuit. Hasil yang diperoleh pada tahap pengembangan adalah dihasilkan LKM berbasis modeleliciting activity yang dapat membangun salah satu skill pada revolusi industry 4.0 yaitu coordinating with other dan layak untuk digunakan pada perkuliahan fisika dasar.

Kata kunci: design and development research, fisika dasar, model-eliciting activity

\section{PENDAhUluAN}

Perkembangan ilmu dan pengetahuan juga diiringi dengan perkembangan revolusi industri. Kesiapan menghadapi revolusi industri yang saat ini telah memasuki revolusi industry 4.0 harus didukung oleh sumber daya yang memadai. Akademisi juga berperan untuk mewujudkan revolusi industri 4.0 (Kagermann et al, 2013). Skill yang dikembangkan pada tahun 2020 meliputi complex problem solving, critical thinking, creativity, people management, coordinating with others, emotional intelligence, judgement and decision 
making, service orientation, negotiation, cognitive flexibility (Word Economic Forum, 2016). Oleh karena itu, dalam proses perkuliahan juga harus mengembangkan kesepuluh top skill tahun 2020 sehingga dapat mendukung revolusi industri 4.0.

Pada program studi teknik elektro, fisika dasar merupakan salah satu mata kuliah wajib yang terdiri dari 3 SKS. Fisika berguna dalam membantu mahasiswa dalam memecahkan masalah pada kehidupan sehari-hari. Instalasi pada rumah misalnya, diperlukan pengetahuan tentang bagaimana cara merangkai rangkaian listrik rumah dengan baik, rangkaian apa yang cocok untuk diterapkan pada rumah sehingga diperoleh cahaya yang terang dan membutuhkan energi yang lebih sedikit sehingga beban pembayaran listik kecil. Pengetahuan dasar tentang instalasi dapat diperoleh dari topik rangkaian hambatan seri dan paralel yang merupakan salah satu topik dalam perkuliahan fisika dasar.

Perkuliahan fisika dasar tidak lepas dari model pembelajaran yang digunakan agar konsep fisika dapat dikuasai oleh mahasiswa dengan baik. Berdasarkan hasil observasi, perkuliahan fisika dasar masih berpusat pada dosen dan mahasiswa belum dilatihkan saling bekerja sama dengan kelompoknya untuk menyelesaikan masalah. Oleh karena itu, diperlukan suatu model pembelajaran yang dapat melatihkan kerja sama antar mahasiswa.

Pada perkuliahan fisika dasar diperlukan lembar kerja mahasiswa untuk mendukung mahasiswa dalam proses penguasaan materi fisika. Lembar kerja mahasiswa yang dibuat dikolaborasikan dengan model pembelajaran yang akan diterapkan. Model eliciting-activity merupakan salah satu model pembelajaran yang dapat melatihkan kerja sama secara berkelompok antar mahasiswa (Wessel, 2014) dan berguna meningkatkan pemecahan masalah (Yu dan Chang, 2009). Oleh karena itu, untuk mendukung perkuliahan fisika dasar pada penelitian ini didesain lembar kerja mahasiswa berbasis model eliciting-activity. Tujuan dari penelitian adalah untuk melihat tingkat keterbacaan dan keterlaksanaan lembar kerja mahasiswa berbasis model eliciting-activity.

\section{METODE PENELITIAN}

Penelitian ini merupakan penelitian pengembangan. Metode penelitian pengembangan menggunakan design and development research (DDR) product and tool research (Richey and Klein, 2007). Fase spesifik terdiri dari analisis, desain, pengembangan, dan evaluasi. Penelitian ini dilakukan pada perkuliahan fisika dasar mahasiswa teknik elektro semester 7 pada salah satu universitas swasta di Lampung yang telah mengikuti perkuliahan fisika dasar.

Pada tahap analisis ini dilakukan analisis terhadap proses perkuliahan, analisis terhadap rencana perkuliahan semester, dan lembar kerja mahasiswa. Pada lembar kerja mahasiswa yang telah ada juga belum melatihkan kerja kelompok. Pada tahapan desain, lembar kerja mahasiswa didesain dengan menggunakan sintaks model eliciting-activity yang terdiri dari yaitu pre-reading, hands on demonstration, a model to predict series and parallel circuit. Pada tahapan pengembangan, desain lembar kerja mahasiswa (LKM) berbasis model-eliciting activity diuji coba kepada mahasiswa untuk melihat keterlaksanaan dan keterbacaannya. Pada tahapan evaluasi dipergunakan untuk mengevaluasi keterlaksanaan dan keterbacaan LKM berbasis model-eliciting activity pada mahasiswa. 


\section{HASIL DAN PEMBAHASAN}

Adapun hasil dan pembahasan dari penelitian yang telah dilakukan adalah:

\subsection{Tahapan Analisis}

Berdasarkan tahapan analisis dan observasi yang telah dilakukan diperoleh kesimpulan bahwa perkuliahan memerlukan penerapan suatu model pembelajaran yang dapat membangun salah satu skill pada revolusi industri 4.0 yaitu coordinating with other (kerja sama antar kelompok) yang dapat dilakukan dengan cara saling bekerjasama dalam memecahkan suatu permasalahan.

\subsection{Tahapan Design}

Desain lembar kerja mahasiswa (LKM) yang dikembangkan berbasis model-eliciting activity. Model-eliciting activity terdiri dari tiga tahapan yaitu pre-reading, hands on demonstration, dan a model to predict material (Moore et al, 2013). Oleh karena itu, lembar kerja yang dikembangkan terdiri dari tiga tahapan model. Pada tahap pre-reading mahasiswa diberikan bacaan untuk dibaca dan dipahami tentang materi rangkaian hambatan seri dan paralel. Pada tahap hands on demonstration mahasiswa dipandu untuk memecahkan masalah secara hands on tentang rangkaian hambatan seri dan paralel. Pada tahapan a model to predict material mahasiswa dipandu untuk menuliskan catatan pertama berhubungan dengan konsep materi rangkaian hambatan seri dan paralel dan catatan kedua berisikan cara pemecahan masalah rangkaian hambatan seri dan paralel yang dapat diterapkan dalam kehidupan sehari-hari.

\subsection{Tahapan Pengembangan}

LKM diuji coba kepada 3 mahasiswa yang telah menempuh perkuliahan fisika dasar. Hasil keterbacaan LKM berbasis model-eliciting activity dalam kategori baik. Dapat dilihat pada Tabel 1.

Tabel 1. Hasil keterbacaan LKM berbasis model-eliciting activity

\begin{tabular}{cccc}
\hline No. & Responden & Skor & Kategori \\
\hline 1 & Mahasiswa 1 & 26 & Baik \\
2 & Mahasiswa 2 & 23 & Baik \\
3 & Mahasiswa 2 & 22 & Baik \\
& Rata-rata & 23,67 & Baik \\
\hline
\end{tabular}

Berdasarkan angket respon yang telah diberikan kepada mahasiswa diperoleh masukan dan saran terutama pada bahasa yang digunakan dalam LKM dan petunjuk pengerjaan tugas harus lebih jelas lagi sehingga mahasiswa dapat lebih memahami tugas yang diberikan. Hasil keterlaksanaan lembar kerja berbasis model-eliciting activity cukup baik. Pada bagian 1 (prereading), bagian 2 (hands on demonstration), dan bagian 3 (a model to predict series and parallel circuit) mahasiswa dalam kategori baik. Rata-rata mahasiswa pada bagian 1 dapat mengerjakan dengan baik dan pada bagian 2 dan 3 saling berkelompok untuk memecahkan masalah. 
Tabel 2. Hasil keterlaksanaan LKM berbasis model-eliciting activity

\begin{tabular}{|c|c|c|c|c|c|c|}
\hline No. & Responden & \multicolumn{3}{|c|}{ Skor } & \multirow[t]{2}{*}{ Nilai } & \multirow[t]{2}{*}{ Kategori } \\
\hline & & bagian 1 & bagian 2 & bagian 3 & & \\
\hline 1 & Mahasiswa 1 & 95 & 90 & 85 & 90 & Baik \\
\hline 2 & Mahasiswa 2 & 80 & 85 & 80 & 82 & Baik \\
\hline 3 & Mahasiswa 2 & 75 & 75 & 75 & 75 & Cukup Baik \\
\hline & Rata-rata & 83 & 83 & 80 & 82 & Baik \\
\hline
\end{tabular}

Berdasarkan Tabel 2, rata-rata nilai untuk bagian 1, 2 dan 3 memperoleh nilai dalam kategori baik dan hanya 1 mahasiswa yang dalam kategori cukup baik. Rata-rata mahasiswa dapat menjawab dan menyelesaikan tugas yang diberikan meskipun masih ada pertanyaan mengenai petunjuk pengerjaan soal.

\subsection{Tahapan Evaluasi}

Tingkat keterbacaan dan keterlaksaan LKM berbasis model-eliciting activity diperoleh dari angket respon yang diberikan kepada mahasiswa dan hasil LKM berbasis model-eliciting activity yang dikerjakan oleh mahasiswa. LKM berbasis model eliciting-activity yang terdiri dari 3 bagian yaitu pre-reading, hands on demonstration, a model to predict series and parallel masih memerlukan perbaikan berdasarkan uji coba yang telah dilakukan. Selanjutnya LKM berbasis model eliciting-activity akan direvisi sesuai dengan saran yang telah diberikan untuk selanjutnya dapat didesain dengan penambahan topik-topik fisika yang lain sehingga dapat mendukung perkuliahan fisika dasar.

\section{KESIMPULAN}

Berdasarkan tahapan analisis, desain, pengembangan, dan evaluasi diperoleh hasil keterlaksanaan lembar kerja mahasiswa LKM berbasis model-eliciting activity dalam kategori baik. Aspek keterbacaan LKM dalam kategori baik dan masih perlu untuk disempurnakan kembali untuk bahasa yang dipergunakan dan petunjuk pengerjaan tugas agar lebih jelas dan dimengerti mahasiswa.

\section{SARAN}

Penelitian lanjut yang akan dilakukan adalah memilih materi lain pada perkuliahan fisika dasar yang cocok untuk diterapkan dan dikembangkan dengan model eliciting-activity. Sehingga dapat terbentuk seperangkat LKM berbasis model-eliciting activity yang dapat mendukung perkuliahan fisika dasar.

\section{DAFTAR PUSTAKA}

Kagermann, H., Lukas, W.D., \& Wahlster, W. (2013). Final report: Recommendations for implementing the strategic initiative INDUSTRIE 4.0. Industrie 4.0 Working Group.

Moore, T. J., Miller, R. L. Lesh, R. A., Stohlmann, M. S., \& Kim, Y. R. (2013). Modeling in Engineering: The Role of Representational Fluency in Students'Conceptual Understanding. Journal of Engineering Education, 102 (1), hlm. 141-178.

Richey R C, and Klein J D 2007 Design and development research (Mahwah NJ: Lawrence Erlbaum Associates Publiser)

Yu, S. dan Chang, C. (2009). What Did Taiwan Mathematics Teachers Think of ModelEliciting Activities and Modeling?. International Conference on the Teaching of 
Mathematical Modeling and Applications, ICTMA Vol 14, University of Hamburg, Hamburg.

Wessels, H. (2014). Levels of Mathematical Creativity in Modeling-Eliciting Activities.Journal of Mathematical Modelling and Applications, 1 (9).

Word Economic Forum. (2016). The future of jobs employment: skills and workforce strategy for the fourth industrial revolution. Global challenge insight report. Retrieved from http://www3.weforum.org/docs/WEF_Future_of_Jobs.pdf. 